NBER WORKING PAPER SERIES

\title{
THE EFFECTS OF INFORMATION, SOCIAL AND ECONOMIC INCENTIVES ON VOLUNTARY UNDIRECTED BLOOD DONATIONS: EVIDENCE FROM A RANDOMIZED CONTROLLED \\ TRIAL IN ARGENTINA
}

\author{
Victor Iajya \\ Nicola Lacetera \\ Mario Macis \\ Robert Slonim \\ Working Paper 18630 \\ http://www.nber.org/papers/w18630 \\ NATIONAL BUREAU OF ECONOMIC RESEARCH \\ 1050 Massachusetts Avenue \\ Cambridge, MA 02138 \\ December 2012
}

We thank Dr. Hugo Medici, Susana Sirena and the staff of the Centro de Medicina Transfusional y Hematologia of San Miguel de Tucuman, Argentina, for their collaboration. Soledad Omodeo provided outstanding research assistance. We benefited from the comments of Margaret McConnell and the participants at the 2012 ASSA Meetings in Chicago, the Workshop on Natural and Field Experiments in Ammersee, the MADS seminar at the Center for Global Development in Washington, DC, the Armstrong Institute at the Johns Hopkins University School of Medicine, Simon Fraser University, Stanford University and the University of British Columbia. Financial support from the Social Sciences and Humanities Research Council of Canada (Grant \#410-2011-1294) and the Johns Hopkins Carey Business School Small Grants Fund is gratefully acknowledged. The views expressed herein are those of the authors and do not necessarily reflect the views of the National Bureau of Economic Research.

NBER working papers are circulated for discussion and comment purposes. They have not been peerreviewed or been subject to the review by the NBER Board of Directors that accompanies official NBER publications.

(C) 2012 by Victor Iajya, Nicola Lacetera, Mario Macis, and Robert Slonim. All rights reserved. Short sections of text, not to exceed two paragraphs, may be quoted without explicit permission provided that full credit, including (C) notice, is given to the source. 
The Effects of Information, Social and Economic Incentives on Voluntary Undirected Blood

Donations: Evidence from a Randomized Controlled Trial in Argentina

Victor Iajya, Nicola Lacetera, Mario Macis, and Robert Slonim

NBER Working Paper No. 18630

December 2012

JEL No. C93,D03,H41,I15

\begin{abstract}
In many low- and middle-income countries blood donations per capita are substantially lower than in advanced economies. In these countries blood supply is mostly collected through donations by relatives and friends of individuals needing transfusions or to replace blood used in emergencies. The World Health Organization considers this method of blood supply inefficient compared to undirected voluntary donations. To examine methods to motivate undirected voluntary donations, we ran a large-scale, natural field experiment in Argentina testing the effectiveness of information, social and economic incentives. We find that only higher-valued economic incentives generated more donations, increasing in the value of the incentive. These incentives did not create adverse selection in the safety and usability of the donated blood. We discuss the implications of our findings for researchers interested in understanding motivations for pro-social behavior and for health agencies and policymakers concerned with the current and growing shortages in blood supply in low- and middle-income countries.
\end{abstract}

Victor Iajya

Av Independencia 1900

San Miguel de Tucumán, (4000), Tucumán Argentina

viajya@herrera.unt.edu.ar

Nicola Lacetera

University of Toronto

105 St. George Street

Toronto, ON M5S 2E9

Canada

and NBER

nicola.lacetera@utoronto.ca
Mario Macis

Johns Hopkins University

Carey Business School

100 International Dr.

Baltimore, MD 21202

mmacis@jhu.edu

Robert Slonim

The University of Sydney

Faculty of Arts and Social Sciences

H04 - Merewether

NSW 2006 Australia

robert.slonim@sydney.edu.au 


\section{Introduction}

Guaranteeing an adequate supply of safe blood is a major health challenge in developing countries where blood shortages are common and have severe consequences (WHO, 2011). ${ }^{1}$ In part, shortages are due to an inefficient blood supply system based on donations by relatives and friends of individuals needing transfusions, or to replace blood used in emergencies. This system might work well for one-time emergencies and in small communities, but is inefficient for chronic needs of blood (e.g., to treat blood diseases and many types of cancer) and in large urban areas with weaker social ties. The World Health Organization (WHO, 2009) argues that a blood supply system based on undirected donations by regular voluntary donors will ensure more donations and provide safer blood by being able to better monitor donors' health conditions. Undirected donations also reduce inefficiencies due to donor-recipient blood incompatibility.

There have been several attempts to create voluntary donation systems to improve the supply of blood in low- and middle-income countries. These efforts typically include the re-organization of blood collection towards a centralized "national blood system" and massive media and educational campaigns to change social attitudes from donating blood to relatives and friends to voluntary undirected donations as a "public good" (Fraser, 2005; Lancet, 2005; WHO, 2009, 2011). These initiatives are financially and organizationally demanding and can take many years to implement. While these efforts may in the long-term be successful, in the short term additional and alternative "micro-level" approaches are available that can be implemented immediately to address the current and growing demand for blood.

In this study we examine three micro-level approaches to motivate blood donations. We assess the impact of (1) information, (2) social prestige and (3) economic incentives on the individual decision to make undirected voluntary blood donations. Specifically, we conducted a natural field experiment in Argentina where $88 \%$ of blood donations are emergency/replacement donations (Ministerio de Salud, 2008).

We chose the specific three treatments because each offers potential benefits associated with motivating undirected donations (rather than motivating emergency donations). First, people are unlikely to be aware of the benefits of a volunteer-based donation system, thus providing this information might be sufficient to increase donations. Second, in developed countries blood

\footnotetext{
${ }^{1}$ The demand for blood transfusions in developing countries is likely to increase dramatically because of population ageing, medical technological advances and general improvements in economic conditions.
} 
donations are often associated with "doing good," thus offering social recognition can increase the benefits donors receive by providing a credible signal of their pro-sociality. Third, the costs to donate (in terms of time or expected pain) may outweigh the pro-social benefits for a substantial share of the population, thus providing economic incentives could tip the tradeoff in favor of donating by increasing the total benefit of donating. However, there are two possible concerns with offering economic incentives. One concern is that extrinsic incentives may conflict with people's intrinsic motives to donate (Benabou and Tirole, 2006; Deci, 1975; Gneezy and Rustichini, 2000). A second issue is that donors motivated by rewards might provide unsafe blood (Abolghasemi et al., 2010; Lancet, 2005; Titmuss, 1971; WHO, 2009). Although both social and economic rewards have been effective in developed countries (DellaVigna et al., 2010; Goette and Stutzer, 2008; Lacetera and Macis, 2010, 2012; Lacetera, Macis and Slonim, 2011, 2012; Rodriguez del Pozo, 1994), responses may differ in other contexts. For instance, whereas giving blood is associated with being pro-social in developed countries, it might carry a negative stigma in developing countries where blood is often (illegally) sold for cash.

To test the effectiveness of information, social and economic incentives to motivate blood donations, we conducted a natural field experiment in September and October 2011. We randomly selected 18,500 individuals aged 18-65 who were residents in San Miguel de Tucuman (SMdT) in northern Argentina. The subjects were sent flyers inviting them to donate at the Centro de Medicina Transfusional y Hematologia (CMTH), a private blood bank in SMdT. Subjects were randomly assigned to seven different flyer conditions that included: (a) one control flyer inviting them to donate; (b) one information flyer that added material on the benefits of voluntary donations; (c) a T-shirt indicating they are blood donors, (d) a mention in the "Socials" page of the local newspaper; and (e) vouchers for a local supermarket in three values (AR\$ 20,60 or 100$)^{2}$

We examine the relative effects of the treatments on both quantity and quality (i.e., usability) of donations. For quantity, we examine both the number of individuals who present to donate and the number of units of usable blood collected. For quality, we assess whether the treatments affected deferral rates and rejection rates after subsequent blood screening tests were conducted.

We find that only the voucher rewards of higher values (AR\$60 and AR\$100) led to positive

\footnotetext{
${ }^{2}$ At the time of the experiment, $\operatorname{AR} \$ 20, \operatorname{AR} \$ 60$ and $A R \$ 100$ were approximately equal to 1.5 hours, 4.5 hours and one days wages, respectively.
} 
(and statistically significant) donation rates, whereas the other treatments did not have any effect. Moreover, the positive effects of the vouchers increased with the economic value of the rewards. We further find that, compared with emergency/replacement donations occurring at the same time at $\mathrm{CMTH}$, the donations of economically incentivized individuals did not lower the blood quality. Thus, economic incentives can effectively motivate individuals to make voluntary, undirected donations in contexts where undirected donations are not the norm.

This is the first study to provide evidence from a randomized controlled trial on the effects of social and economic incentives on undirected blood donations in a setting where the prevailing social norm is to make donations directed to specific recipients. Moreover, previous studies have typically only examined individuals who had already given blood in the past whereas the sample in this study is taken randomly from the general population and thus includes mostly non-donors. In further contrast to existing studies, we are also able to distinguish ineligible-to-donate and rejected blood units in order to explore the exact reasons for non-usable donations. Finally, this study contributes to a growing stream of research that highlights the role of field experiments in providing policy-relevant evidence to tackle major problems in global health and development. ${ }^{3}$

The following section describes the study setting and Section 3 presents the experimental design. Section 4 reports and discusses the empirical findings, Section 5 provides a cost-benefit analysis of the intervention and Section 6 offers concluding remarks.

\section{Study Setting and Design}

\subsection{Blood donations in Argentina, Tucuman and CMTH}

Like most low- and middle-income countries, blood shortages in Argentina are frequent and, due to increasing life expectancy and technical advances (e.g., in surgery and transplants), likely to worsen without improvements in supply. In 2002, the Argentine Health Ministry launched a "National Blood Plan" aimed at creating awareness about blood donations and increasing the number of voluntary blood donors. Following WHO recommendations, the National Blood Plan aims to foster voluntary unpaid donations. In terms of total blood collected, Argentina performs better than most transitional economies with 12.4 donations per 1,000 persons in 2008 (Ministerio de Salud, 2010), but this rate is still well below the 38 per 1,000 persons (WHO,

\footnotetext{
${ }^{3}$ See for example Ashraf, Berry and Shapiro, 2010; Ashraf, Bandiera and Jack, 2012; Cohen and Dupas, 2010; Dupas, 2011; Baird et al. 2012, Duflo et al. 2012; Okekea, Adepitib and Ajenifujab, 2012; deWalque et al., 2012.
} 
2011) in developed countries. Further, the average masks significant regional differences. For instance, there are 14 donations per 1,000 persons in the Central region (where Buenos Aires is located) but only 9 donations per 1,000 persons in the Northeast (where SMdT is located). According to the Health Ministry, the plan has increased the number of voluntary donors. Nonetheless, the Argentine system still relies heavily on emergency/replacement donors which in 2008 still represented $88 \%$ of all blood collected.

We conducted our experiment with the Centro de Medicina Transfusional y Hematologia $(\mathrm{CMTH})$ in SMdT, the capital of the Tucuman province in northeastern Argentina. CMTH is one of seven private blood banks in Tucuman that collect roughly $2 / 3$ of blood (the Ministry of Health collects the remaining 1/3). In 2011, CMTH collected 3,220 units of (mostly) whole blood from 3,139 emergency-replacement donors. CMTH collects approximately $25 \%$ of all donations in Tucuman. CMTH is centrally located in downtown SMdT and is easily accessible by car or public transportation. All the addresses of individuals receiving invitations to donate were within 15-minute drive of CMTH. The location and easy access makes non-donations due to the location an unlikely explanation for not responding to the invitation to donate.

\subsection{Experimental design and Implementation details}

The subject population of our experiment consisted of 18,500 individuals randomly selected from SMdT's electoral list and includes all citizens who were at least 18 years old. ${ }^{4}$ Each subject was invited to make an undirected voluntary blood donation (rather than to make an emergency donation for a relative or friend). The subjects were randomly assigned to one of the following seven flyer conditions: ${ }^{5}$

T0 (Baseline: Invitation only): Individuals received a flyer sent by CMTH inviting them to donate blood.

\footnotetext{
${ }^{4}$ We obtained authorization to access the electoral list from a member of the Provincial Congress ("Legislatura") of the Province of Tucuman.

${ }^{5}$ The electoral lists contained each person's National Identity Number ("DNI," Documento Nacional de Identidad). A person's DNI is a progressive number assigned at birth by the "Registro Nacional de las Personas" (National Registry of People). Within each province of birth, the DNI is not related to any specific individual characteristic (e.g., it is not systematically related to gender or parents' address); it is simply an increasing function of birth date. Thus, we can use it to test the random assignment of subjects to treatment conditions. Figure 3 shows the distribution of DNIs in the seven experimental conditions. The figure shows that the seven distributions are nearly identical, indicating successful randomization. After performing the intervention, we deleted any individual identifying information from our records (specifically, name and DNI) and replaced it with a "study ID" number. Further, only CMTH (not the authors) is aware of the identity of the subjects who presented to donate and of the outcome of the donation (i.e., whether the donor was ineligible, whether her donation was discarded, etc.).
} 
T1 (Information): $\mathrm{T} 0+$ the flyer indicated the importance of voluntary, undirected donations as opposed to emergency/ replacement donations.

T2 (T-Shirt): T1 + the flyer indicated that if they presented at CMTH within three weeks, recipients would receive a t-shirt indicating that they are a blood donor.

T3 (Newspaper mention): $\mathrm{T} 1$ + the flyer indicated that if they presented at CMTH within three weeks, recipients' contribution would be recognized in the local newspaper ("La Gaceta").

T4, T5, T6 (Vouchers): T1 + the flyer indicated that if they presented at CMTH within three weeks they would receive a coupon worth AR $\$ 20$ (T4), AR\$60 (T5), or AR \$100 (T6) for a local supermarket chain ("VEA"). The coupons were not refundable or redeemable for cash. AR $\$ 20$ (US\$4.6) was approximately equal to 1.5 hours average wages.

Thus treatment $\mathrm{T} 0$ serves as our baseline control, treatment $\mathrm{T} 1$ examines the role of information, treatments $\mathrm{T} 2$ includes both an economic component (a t-shirt) and a social image component (the indication of donor status on the t-shirt), T3 considers a purely social-image incentive, and T4-T6 examine purely economic rewards. ${ }^{6}$ We randomly assigned 2,500 subjects to the first six treatments (T0-T5) and 3,500 to the highest valued economic incentive treatment (T6). ${ }^{7}$ Figure 1 shows the experimental design and the number of flyers successfully delivered for each treatment. The mailing company was unable to deliver 1,262 flyers due to logistical issues such as the recipient having relocated or having become deceased. On average, the undelivered flyers were $6.8 \%$ per condition, with no single treatment deviating substantially (or significantly) from this average. Figure 2 shows the original flyers and their English language translations.

The treatments were run sequentially to minimize contamination. Subjects in T2 and T4-T6 were mailed flyers on September $2^{\text {nd }}, 2011$ and given until September $23^{\text {rd }}$ to present to donate in order to receive the reward. Subjects in T0, T1 and T3 were mailed flyers on September $23^{\text {rd }}$ and were encouraged to donate by October $14^{\text {th }}$. This order of the flyer conditions avoided subjects

\footnotetext{
${ }^{6}$ To give a sense of the purchasing power of the vouchers, here are the prices of some popular items sold in the local department store: 1.5 liter bottle of Coke: AR \$9.19; 1 liter of milk: AR $\$ 6.95 ; 0.5$ kilos Spaghetti: AR $\$ 5.85$.

${ }^{7}$ We included an extra 1,000 subjects in the AR $\$ 100$ treatment to give us the most power to detect effects in the condition that we had a priori hypothesized, based on work in developed countries (Lacetera, Macis and Slonim 2012a, 2012b) would have the largest effect. If our results had shown no effect in this condition, we would then have had the most power to be confident of a null result. However, since we find a significant effect in this condition, we do not need to worry about power.
} 
presenting to donate and receive a reward (T2, T4-T6) at the same time that subjects in the other conditions not receiving rewards (T0, $\mathrm{T} 1, \mathrm{~T} 3)$ would present to donate.

A few final details of the study design are worth mentioning. First, the subjects were unaware that they were participating in a study. Thus, responses were not influenced by "experimenter effects" or social desirability biases (Levitt and List, 2007; List, 2008). Second, subjects interacted exclusively with CMTH personnel if they presented to donate. Third, all donations took place at CMTH's one physical location. When a donor arrived at CMTH, she was directed to a receptionist who collected personal information. Then, the donor was sent to a separate room where she was asked to complete a questionnaire aimed at assessing her health history and determining whether she engaged in "risky" behaviors (e.g., travel to malaria-prone regions, unprotected sexual activities). Next, provided that there were no "red flags" in her answers, the actual blood draw took place. The whole process typically took an hour. Finally, and consistent with developed country procedures to eliminate the risk of coercion or any incentive to misrepresent medical history, receipt of the rewards in T2-T6 was not conditional on donating, being eligible to donate or completing the questionnaire.

\subsection{Donor characteristics}

Although we do not have individual-level data on the people to whom flyers were mailed, we asked all presenting donors to complete an anonymous survey regarding demographics (gender, age) and other individual characteristics such as education, occupation and income. Table 1 shows the responses for all donors who responded to the survey in the reward treatments (Column 1). ${ }^{8}$ For comparison, we show the same information for all residents in SMdT ages 1865 (Column 2). Compared to the population, presenting donors were (1) less likely to be female (subjects: 41\%; population: 51\%), (2) younger (average age of subjects: 32.0 ; population: 37.4 ) and more educated (e.g., $48 \%$ of subjects completed at least high school vs. only $30 \%$ of the population). ${ }^{9}$ The income distribution of the presenting donors is comparable to the distribution in SMdT.

\footnotetext{
${ }^{8}$ Only one person presented for any of the other treatments.

${ }^{9}$ These donors are considerably younger, compared to other populations of blood donors that have been studied in the literature, but present a comparable gender composition: the Swiss donors studied in Goette and Stutzer (2008) were $41 \%$ female and 43 years old on average, and the American donors studied in Lacetera, Macis and Slonim (2012b) were $51 \%$ female and on average 41 years old.
} 


\section{Results}

The outcomes we examine are whether subjects presented at CMTH ("turnout"), whether they made a usable donation ("productive units"), the reasons for unsuccessful blood collection such as ineligibility for medical reasons ("ineligible donors") or walking away before donating ("walkouts"), and the blood testing positive for infectious diseases ("discarded units"). The findings are reported graphically in Figures 4 and 5. In Tables 2 and 3 we report estimates of the following simple empirical model:

$$
y_{i}=\sum_{k=0}^{6} \alpha_{k} T_{k, i}+\varepsilon_{i},
$$

where $i$ denotes subject $i, y_{i}$ denotes one of the outcomes of interest, and the binary indicators $T_{k}$ represent the seven experimental conditions T0-T6. The estimates $\hat{\alpha}_{k}$ are the treatment effects, which we report in absolute value as well as difference from the control or information conditions.

Our study provides four key results. We first discuss turnout and productive units collected and then we discuss the quality of the units collected.

\subsection{Turnout and Productive Units Collected}

Figure 4 and Table 2 show the statistics on turnout and on the total units collected for each condition. Our first key result is that we find no effect of information or social image on donations. The turnout rate was $0.04 \%$ in the control condition (T0) and no one presented in the condition only providing information (T1), offering a t-shirt with blood donor indication (T2) or name mention in the newspaper (T3). It is surprising that $t$-shirts as well as forms of public recognition had no effects on motivating donations given the findings in developed countries (Lacetera and Macis, 2010; Lacetera, Macis and Slonim, 2012). We discuss possible explanations for this result below.

Second, offering the larger economic rewards of AR $\$ 60$ and AR $\$ 100$ led to significant increases in donations. The turnout rate was $0 \%, 0.51 \%$ and $1.13 \%$ in the AR $\$ 20, \operatorname{AR} \$ 60$ and $\mathrm{AR} \$ 100$ treatments, respectively. The AR $\$ 60$ and AR $\$ 100$ effects are statistically significant $(p<.01)$ compared to the information only condition. Moreover, the AR $\$ 100$ increase in donations is also statistically different $(p<.05)$ than the AR $\$ 60$ increase. The treatment effects are also large and significant when we consider productive (usable) donations as the outcome variable. The AR $\$ 60$ and AR $\$ 100$ rewards increased the likelihood of collecting a usable blood 
unit by 0.43 and 0.98 percentage points, respectively, and the effects are again statistically significant compared to the information only condition.

Third, disaggregating the effect of the economic incentives, we find that they attracted both individuals who we had and had not mailed flyers to. Among the 12 individuals who presented with the AR\$60 flyer, 10 were on the list we mailed flyers to and 2 were not. Among the 37 individuals who presented with the AR $\$ 100$ flyer, 27 were on the list and 10 were not. The 12 individuals who presented but were not on the mail lists either came with someone who was contacted $(\mathrm{N}=8)$ or provided a flyer that was sent to someone else $(\mathrm{N}=4)$. Thus, in addition to a direct positive effect of incentives on subjects we mailed flyers, we also detect an indirect effect on individuals who were not contacted yet learned about the rewards and presented to donate.

Evidence on the direct effect is presented in Table 3. The AR $\$ 60$ voucher increased the likelihood that a contacted subject made a productive donation by 0.34 percentage points compared to the information only condition $(p<.01)$. The corresponding increase for the AR $\$ 100$ condition was 0.74 percentage points $(p<.001)$. Further, offering AR $\$ 100$ increased donations by 0.44 percentage points compared to the $\mathrm{AR} \$ 60$ offer $(p=0.071)$.

The magnitude of the indirect effects is also non-trivial. Of the 49 individuals who responded to the AR $\$ 60$ and AR $\$ 100$ offers, 17\% (2/12) and 27\% 910/37), respectively, were individuals who had not been mailed flyers. ${ }^{10}$ These results are consistent with Lacetera, Macis and Slonim (2011) who found that offering economic rewards to existing blood donors in the U.S. increased the donations of non-contacted donors and new donors. Moreover, Lacetera, Macis and Slonim $(2011,2012)$ also found that the effects are strongest for their highest valued economic incentive.

The overall response rates to the AR $\$ 60$ and AR $\$ 100$ reward offers are quite substantial considering that (1) we asked for voluntary undirected blood donations rather than follow the norm and ask for donations directed to a specific person familiar to the donors, and (2) we targeted the general population rather than individuals who had already given blood before. For comparison, response rates to direct mailings soliciting monetary donations to charitable organizations typically range between 0.5 and 2.5 percent (Turner, 2002), and these fundraising

\footnotetext{
${ }^{10}$ We ran identical analyses for the indirect effects to the one presented in Table 2 for the direct effects. The results show that the indirect effect of the AR $\$ 60$ offer is positive but not significant, whereas the AR $\$ 100$ offer induced a significant 0.31 percentage point increase in donors presenting who had not been officially contacted $(p=.007)$, and a significant 0.25 percentage point increase in productive donations $(p=.024)$. However, these statistical results should be cautiously interpreted since we do not know whether each observation is independent (some subjects came together).
} 
efforts are usually targeted at individuals who are a priori more likely to give (e.g., individuals with higher incomes or who live in certain neighborhoods).

\subsection{Walkouts, Ineligible Donors and Discarded Donations}

The fourth key result is that offering the larger economic rewards did not negatively affect usable blood donations. Although our intention was to compare the quality of the donations in the treatments to the quality in the control and information conditions, this is impossible since there was only one donation in the control and information-only treatments. Instead, we compare the quality of the donations when subjects were offered incentives to the 3,220 emergency donations made in 2011 at CMTH. While a comparison of the incentives conditions to the information only conditions would have allowed us to focus on the unique impact of incentives, comparing the quality of the donations in the incentives conditions to emergency/replacement donations is perhaps the most important comparison for policy since it indicates whether changing the motivation away from emergency only donations to undirected voluntary donations affects blood supply safety.

The results of these comparisons are presented in Figure 5 and Table 4. We detected no significant difference in the share of ineligible individuals (2/49 [4.1\%] vs. 112/3,220 [3.5\%]) or of donations testing positive for an infectious disease (2/44 [4.5\%] vs. 120/2,974 [4.0\%]). Adding blood type mismatch to the causes of ineligibility, the share of ineligible individuals was actually higher among the emergency/replacement group $([112+68] / 3,220=5.59 \%)$. This later result highlights a problem that is not often stressed with regard to emergency/replacement donations; by relying on a restricted pool of donors for a specific recipient, there is a nonnegligible chance of donor-receiver blood incompatibility. This is rarely the case with undirected volunteer donations. Last, we also find that the share of walkouts is higher among the individuals who responded to economic incentive offers $(3 / 49=6.12 \%)$ than for the emergency donors $(56 / 3,220=1.74 \%)$. This indicates that a downside of offering economic incentives may be to motivate opportunistic (unproductive) behavior.

Overall, the share of usable units collected from the AR $\$ 60$ and AR $\$ 100(42 / 49=85.7 \%)$ was not statistically different from the share among emergency/replacement donors $(2,864 / 3,220=88.9 \%)$. The shares are even more similar to each other if we exclude the walkouts (91.3\% vs. $90.5 \%)$ and if we exclude the cases of blood type incompatibility $(91.3 \%$ vs. $92.5 \%)$. These results suggest that economic incentives did not disproportionately trigger adverse 
selection in the likelihood of collecting usable blood compared to the emergency/replacement approach to collect blood.

\subsection{Follow-up and long-term effects}

To assess the long-term impact of the treatments, we ran a follow-up intervention in which we sent invitations to donate to (a) all individuals who made a successful donation in response to one of the voucher treatments, (b) a random sample of 350 individuals per treatment who did not donate during the intervention, and (c) 500 new individuals randomly selected from the electoral list. The follow-up flyers were sent February $3^{\text {rd }}, 2012$ when everyone who had donated during the intervention was eligible to donate again. Subjects were invited to donate by March 1, 2012. They were told they could either present to donate at CMTH or call to make an appointment. In the follow-up, none of the individuals were offered any further incentive; the goal of our followup study was to measure individuals' propensity to donate once incentives have been removed.

The results of the follow-up intervention are easily summarized: None of the individuals contacted in the follow-up intervention presented to donate by the suggested deadline and none presented for at least another six months thereafter that we have obtained data from CMTH. This indicates that the effect of the incentive offer was limited to the time it had been offered.

\section{Cost-benefit analysis}

Beside the academic relevance in understanding whether incentives can increase pro-social behavior in the context of blood donations in a developing economy, an important policy question is whether offering incentives is financially feasible to address blood shortages. This is particularly pressing in developing countries where financial constraints are likely to be tight.

To determine the cost per productive unit of blood collected, we proceed as follows (and Table 5 concisely shows the estimates). First, the cost of printing and mailing the flyers to individuals in conditions T5 and T6 was AR $\$ 1.8$ X 6,000 mailed $=\mathrm{AR} \$ 10,800$. Second, the cost of the vouchers for those who presented was AR $\$ 60 \times 12+\mathrm{AR} \$ 100 \times 37=\mathrm{AR} \$ 4,420$. Thus, the total cost to print and mail the flyers plus provide the vouchers to donors was AR $\$ 15,220$. This can be disaggregated into the total costs of $\operatorname{AR} \$ 5,220$ and AR $\$ 10,000$ for the AR $\$ 60$ and AR $\$ 100$ offers, respectively. Because there were 10 and 32 productive units collected in the $\mathrm{AR} \$ 60$ and $\mathrm{AR} \$ 100$ conditions, respectively, the cost per productive unit was AR $\$ 522$ 
(US\$120) and AR\$312 (US\$72). These estimates ignore the incremental costs that CMTH incurs in their operations to collect, process, and store each additional unit. ${ }^{11}$

Estimating the social benefit from collecting one extra unit of blood is difficult (Lacetera, Macis and Slonim 2012). A lower bound is the amount reimbursed by insurance companies ("Obras Sociales") to blood banks for each unit of whole blood. Based on conversations with local physicians, in 2011 in Argentina this reimbursement rate ranged between AR $\$ 405$ and AR $\$ 620$. Another approach is to consider the value of the potential uses of the blood collected. For example, about seven units of blood are needed for brain surgery or hip replacement, and for a week's treatment for an average cancer patient. Although the variation in the expected benefits from a blood unit is large due to the many possible uses, it is reasonable to assume that the benefits will easily outweigh the per-unit costs that we have estimated.

\section{Discussion and implications}

Our results indicate that an individual micro-level approach that includes both information and an economic reward can be effective in stimulating undirected donations whereas social recognition incentives and information alone were not effective. These results are consistent with evidence from developed economies where economic incentives were also found to positively affect donations (Lacetera, Macis and Slonim 2011, 2012), but in contrast to evidence showing that social recognition also improves donations (Lacetera and Macis, 2010). The contrasting evidence on the effects of social recognition (even when coupled with immediate economic value, as in the case of t-shirts) underscores the importance of understanding local contexts and norms that can differ from country to country and lead to different responses.

We also found that incentives did not increase the share of ineligible subjects or the share of non-usable donations compared to emergency/replacement donors. This evidence is consistent with Lacetera, Macis and Slonim (2012) who also report no negative effects on the quality of blood donations when incentives are offered. The current results add to their findings since we targeted here a population who have never donated before whereas Lacetera et al. (2012) examined existing donors. Combining these two studies, the only two that have directly examined the effects of economic incentives on the quality of blood donations, the evidence

\footnotetext{
${ }^{11}$ The costs associated with the three walkouts (AR $\left.\$ 300\right)$, the only significantly larger effect on the reduction in units collected in the incentive conditions, is under $2 \%$ of the total costs $(=\operatorname{AR} \$ 300 / \operatorname{AR} \$ 15,220)$.
} 
contrasts Titmuss' (1971) conjecture that offering rewards for donations would necessarily lead to a lower quality of blood donations.

In sum, we find that economic incentives increased the pro-social behavior of blood donations in a developing economy. This conclusion is consistent with several recent studies that have shown how individual-level economic rewards positively affect behavior and help alleviate other major health and social problems in developing countries (Baird et al. 2012, Duflo et al. 2012, deWalque et al. 2012).

We conclude by pointing out some directions for future research. First, studies in more countries and contexts (e.g., in rural areas) would be useful to further examine the robustness of the effects of individual economic incentives to address major social problems. Second, alternative ways to approach potential donors (e.g., phone calls and even more personal contact in group or individual settings such as churches and offices) could help us understand the importance of social distance and the interactions of social distance and incentives on pro-social responses. Third, examining whether offering incentives one time or across multiple periods could induce different responses has received little attention in the literature. For instance, repeatedly offering an incentive could potentially lead to habit formation of the pro-social activity (Charness and Gneezy, 2009; Royer, Stehr and Sydnor, 2012) or alternatively could result in reduced effects as people get desensitized to the incentive. In the meantime, the current study indicates that an individual micro-level approach of offering economic incentives can effectively increase donations without adversely affecting the usability or quality of donations. 


\section{References}

Abolghasemi, H., Hosseini-Divkalayi, N.S., Seighali, F., 2010. "Blood donor incentives: A step forward or backward." Asian J Transfusion Science 4: 9-13.

Ashraf, N., Bandiera, O. and Jack, K., 2012. "No margin, no mission? A field experiment on incentives for pro-social tasks," CEPR working paper.

Ashraf, N, Berry, J., and Shapiro, J., 2010. "Can higher prices stimulate product use? Evidence from a field experiment in Zambia.” American Economic Review, 100(5): 2383-2413.

Baird S.J., Garfein, R.S., McIntosh C.T., and Özler, B., 2012 "Effect of a cash transfer programme for schooling on prevalence of HIV and herpes simplex type 2 in Malawi: a cluster randomised trial," The Lancet 379(9823): 13201329.

Bénabou R, Tirole J., 2006. "Incentives and pro-social behavior,” American Economic Review 6(5): 1652-1678.

Charness, G. and Gneezy, U., 2009: "Incentives to exercise," Econometrica, 77(3): 909-931.

Cohen, J., and Dupas, P., 2010. "Free distribution or cost-sharing? Evidence from a randomized malaria prevention experiment," Quarterly Journal of Economics, 125(1): 1-45.

Deci, E.L., 1975: Intrinsic Motivation, New York and London: Plenum Press.

DellaVigna S., List J., and Malmendier, U., 2012: "Testing for altruism and social pressure in charitable giving," Quarterly Journal of Economics, 127: 1-56.

de Walque D., Dow W.H., Nathan R., et al. 2012. "Incentivising safe sex: a randomised trial of conditional cash transfers for HIV and sexually transmitted infection prevention in rural Tanzania," BMJ Open 2(1). Available: http://bmjopen.bmj.com/content/2/1/e000747.short. Accessed 21 July 2012.

Duflo E., Hanna R., and Ryan S., 2012. "Incentives work: Getting teachers to come to school," American Economic Review," In press.

Dupas, P., 2011: "Health behavior in developing countries," Annual Review of Economics, 3: 425- 449.

Gneezy U., and Rustichini, A., 2000: "Pay enough or don't pay at all," Quarterly Journal of Economics, 115(3): 791-810.

Lancet, 2005: "Blood supply and demand," Editorial, The Lancet 365(9478): 2151.

Fraser, B., 2005: “Seeking a safer blood supply,” The Lancet 365(9459): 559-560.

Goette, L., and Stutzer, A., 2008: "Blood donation and incentives: Evidence from a field experiment," IZA Discussion Paper 3580.

Lacetera N., and Macis M., 2010: "Social image concerns and pro-social behavior: Field evidence from a nonlinear incentive scheme," Journal of Economic Behavior and Organization, 76: 225-237.

Lacetera, N., Macis, M., 2012: “Time for blood: The effect of paid leave legislation on altruistic behavior," Journal of Law, Economics \& Organization. In press.

Lacetera, N., Macis, M., and Slonim, R., 2011: “Motivating altruism? A natural field experiment,” NBER Working Paper 17636.

Lacetera, N., Macis M., and Slonim, R., 2012. "Will there be Blood? Incentives and Displacement Effects in Pro-Social Behavior," American Economic Journal - Economic Policy, 4(1): 186-223.

Levitt, S., and List, J., 2007: "What do laboratory experiments measuring social preferences reveal about the real world?," Journal of Economic Perspectives, 21(2): 153-174.

List, J., 2008. "Informed consent in social science," Science 322(5902): 672.

Ministerio de Salud, 2008. "Sistema Nacional de Sangre," Revista Argentina de Salud Publica, March issue."

Rodriguez del Pozo, P., 1994: "Paying donors and the ethics of blood supply," Journal of Medical Ethics, 20: 31-35.

Royer, H., Stehr, M. and Sydnor, J., 2012: "Incentives, commitments and habit formation in exercise: Evidence from a field experiment with workers at a Fortune-500 company," NBER Working Paper 18580.

Titmuss, R.M., 1971: The Gift Relationship, London: Allen and Unwin.

Turner, M.A., 2002: "The impact of data restrictions on fundraising for charitable \& nonprofit institutions", Information Services Executive Council.

WHO, 2009: Global Consultation. "100\% Voluntary Non-Remunerated Donation of Blood and Blood Components, Melbourne, 9-11 June 2009. Geneva: World Health Organization.

WHO, 2011: Fact sheet $N^{\circ} 279$, Geneva: World Health Organization. 


\section{Figure 1: Trial profile}

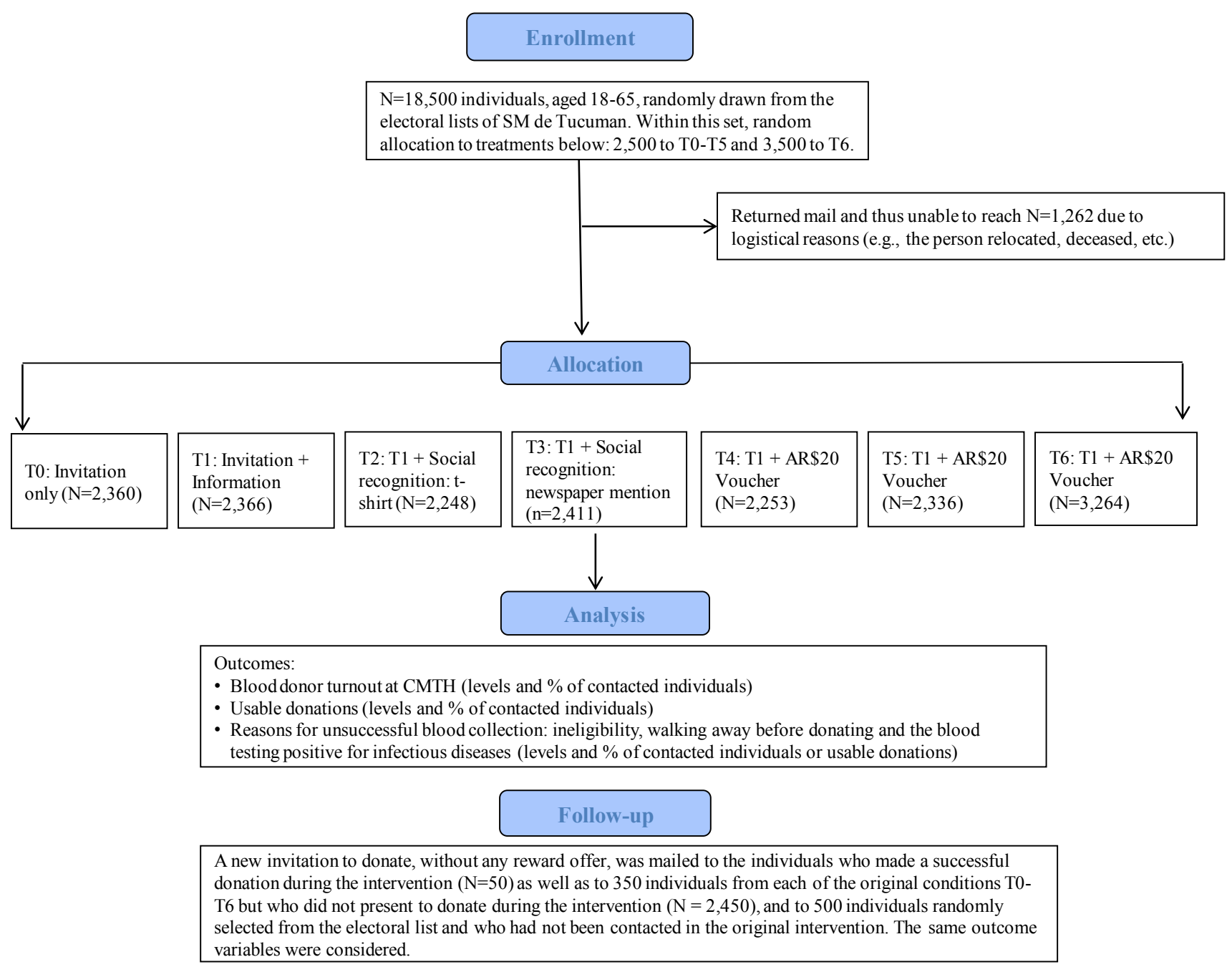


Figure 2: Flyers used in the experiments, and their explanation and translation

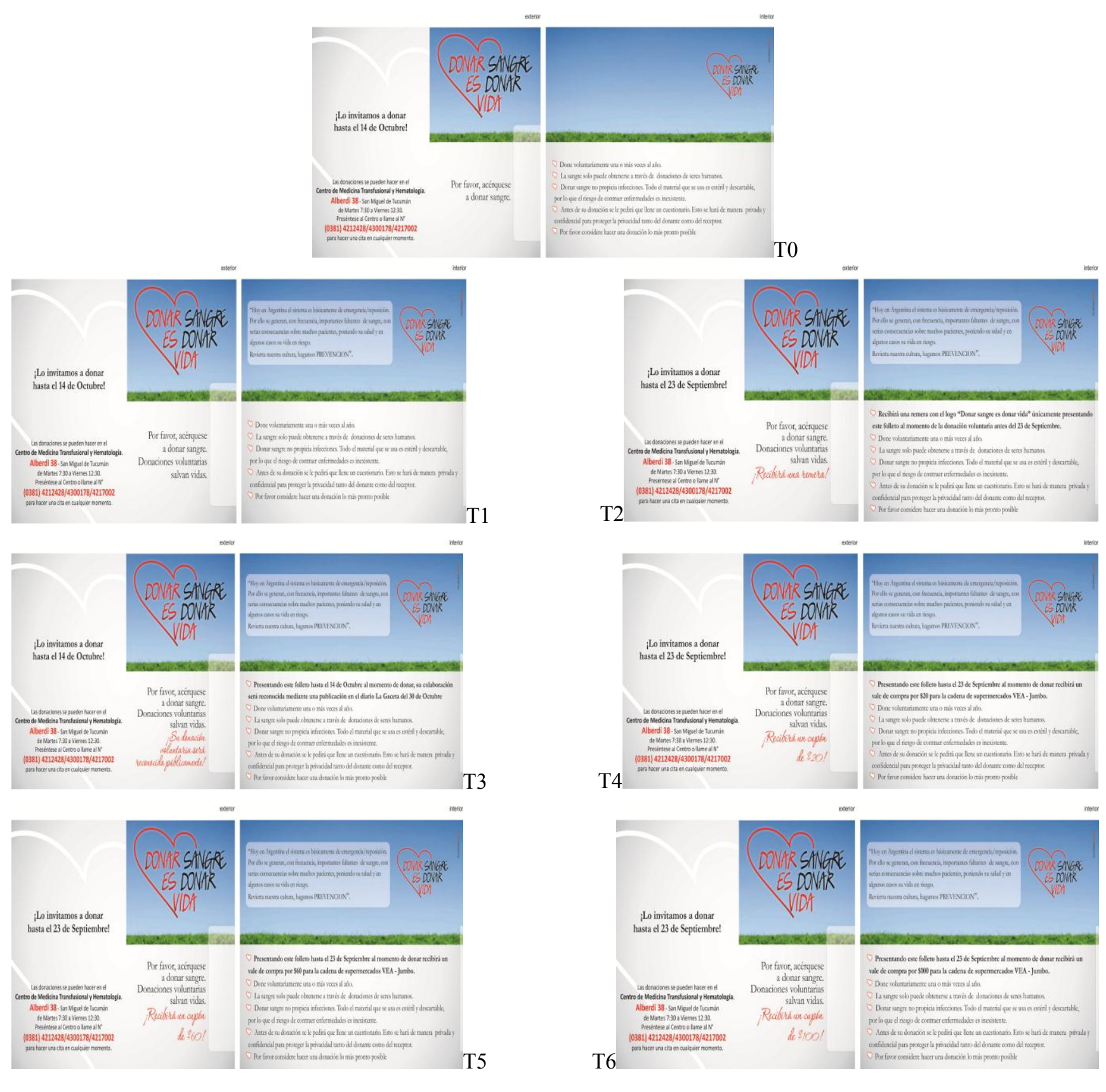

[Continues on the next page] 


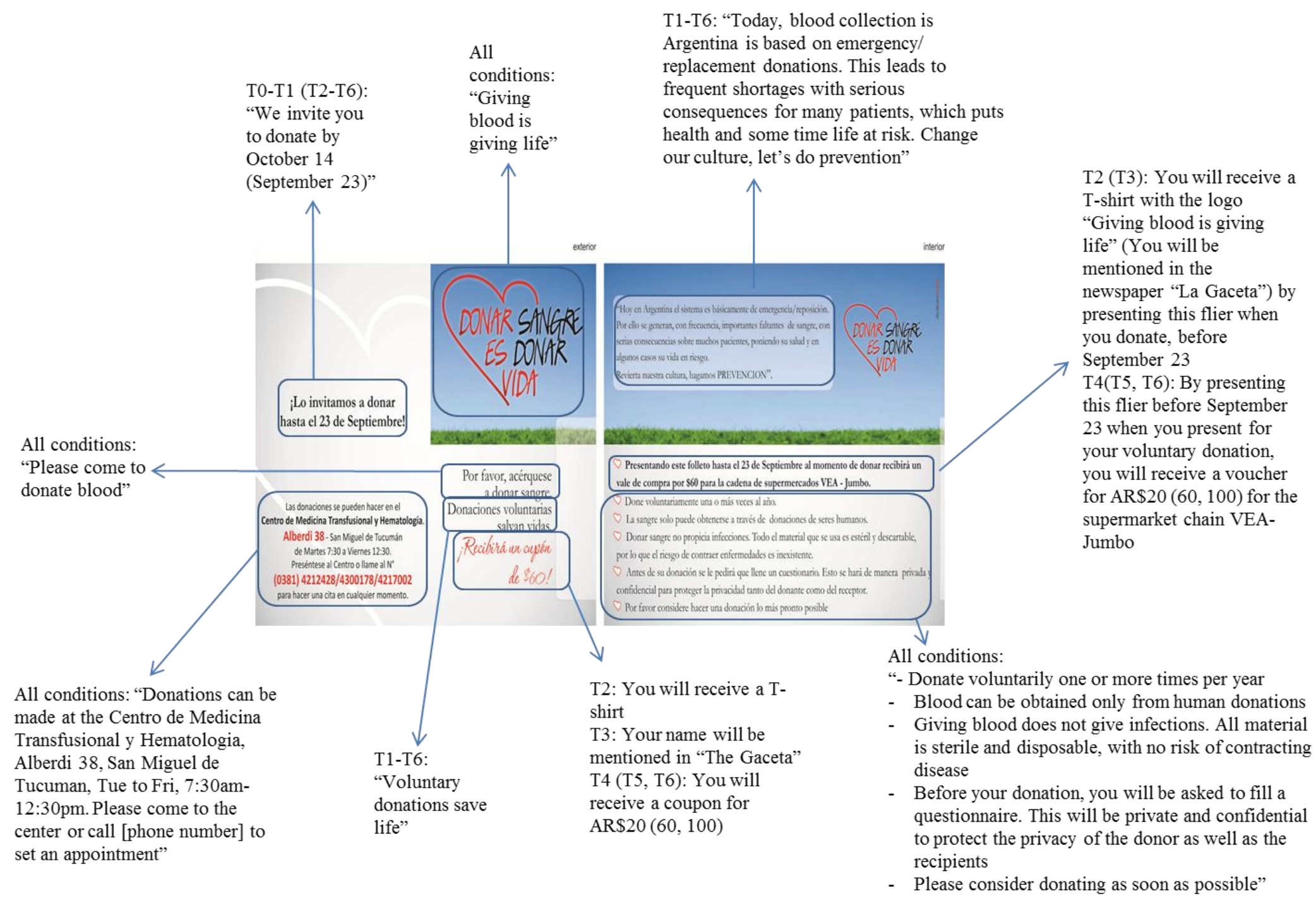




\section{Figure 3: Randomization Check (Distributions of ID Numbers)}

We test for the effectiveness of our assignment of subject into treatments based on random selection of the "DNI", Documento Nacional de Identidad. This number is assigned at birth at birth by the "Registro Nacional de las Personas" (National Registry of People). Within province of birth, the number is not related to any specific individual characteristic (e.g., it is not systematically related to sex or parents' address) and is thus simply an increasing function of birth date. The figure shows the distribution of this ID number across treatments. After performing the intervention, we deleted any individual identifying information from our records and replaced it with a "study ID" number. Further, only CMTH is aware of the identity of the subjects who presented to donate and of the outcome of the donation (i.e., whether the donor was ineligible, her donation discarded, etc.).

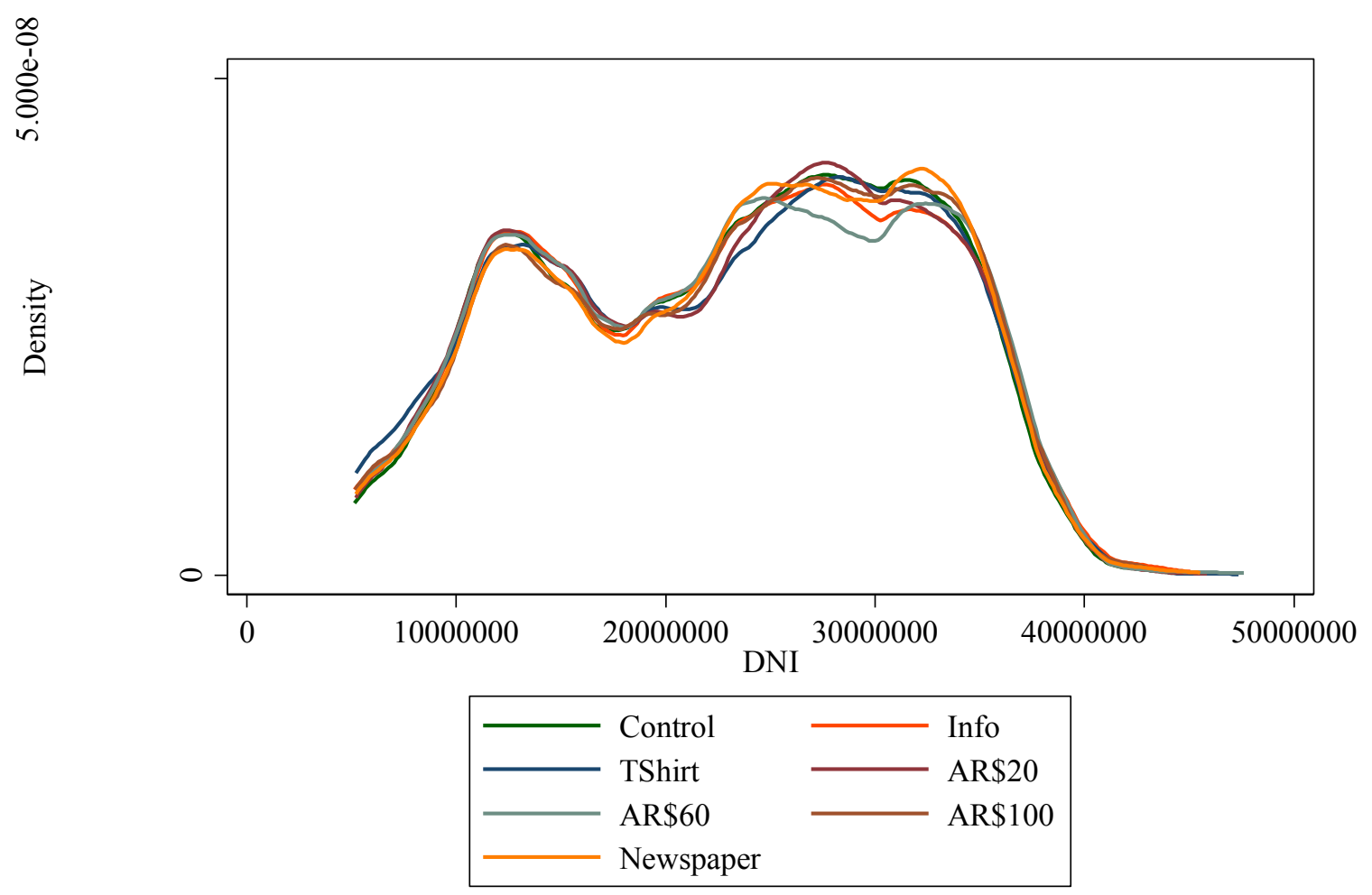


Figure 4: Experimental results -- Donor turnout and productive blood units

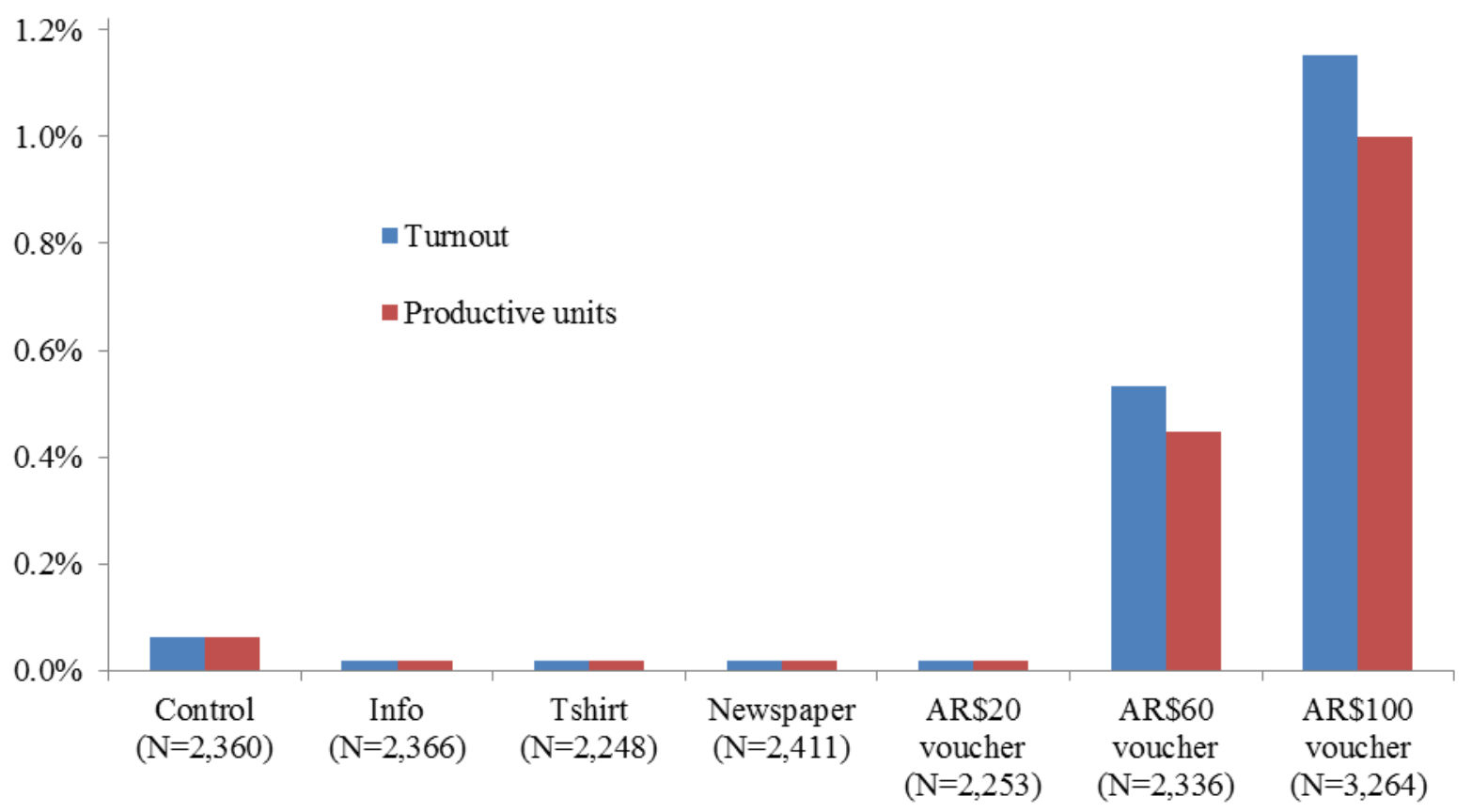


Figure 5: Experimental results -- Walkouts, ineligible donors, and discarded units

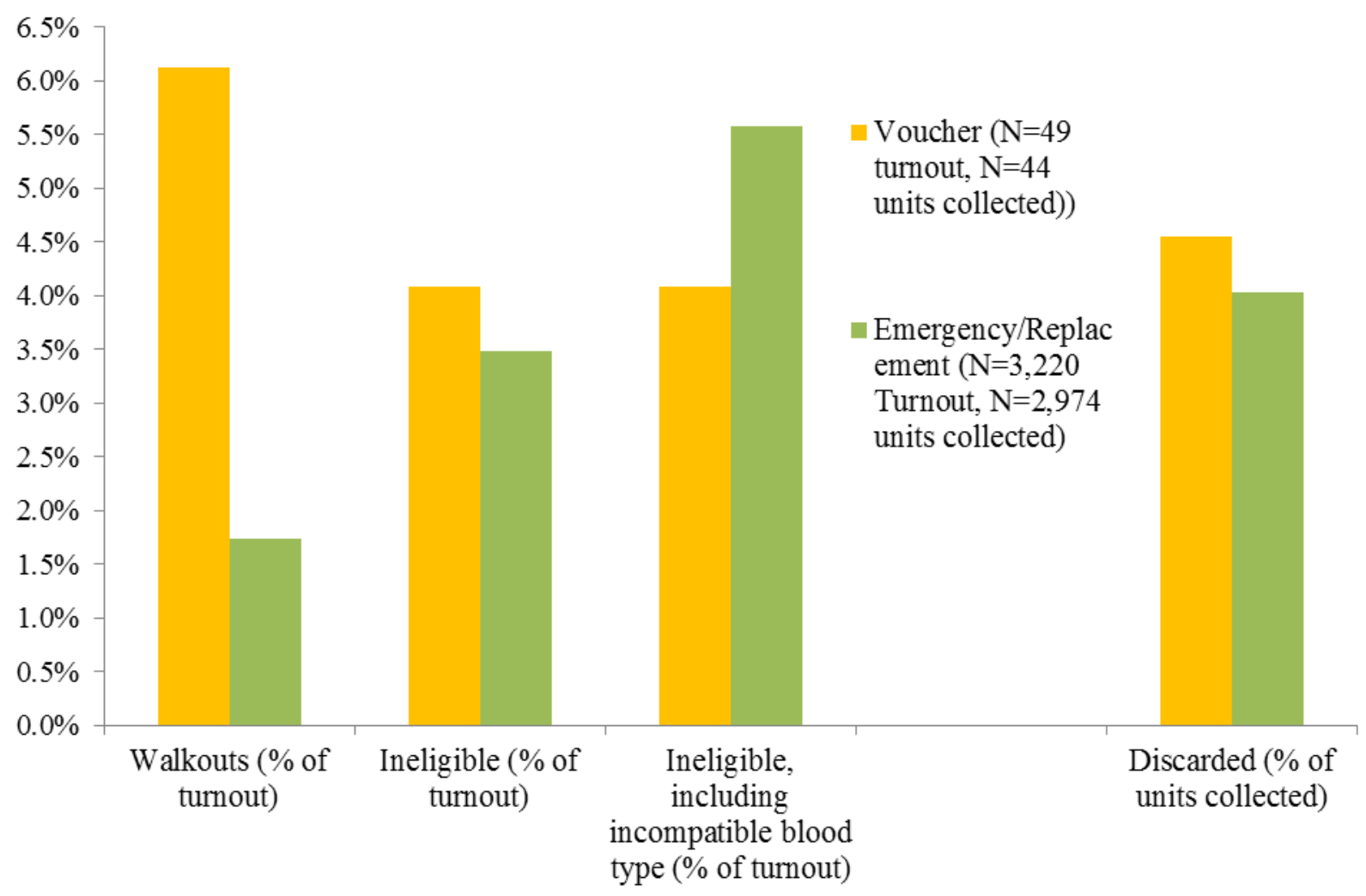




\section{Table 1: Individuals' characteristics of presenting donors and SMdT residents}

The first column of this table reports summary information (averages and standard deviations) for the overall population between 18 and 65 years of age in SMdT, using data from INDEC Censo 2010 (age and gender), INDEC Censo 2001 (education); and INDEC, Encuesta Permanente de Hogares (EPH) Segundo Trimestre 2011 income). The statistics in the second to fourth columns are based on information collected from a questionnaire that was administered to individuals presenting at the blood bank.

\begin{tabular}{|c|c|c|}
\hline & Tucuman (18-65) & $\begin{array}{c}\text { All "voucher" } \\
\text { donors }\end{array}$ \\
\hline Female & 0.51 & 0.41 \\
\hline \multirow[t]{2}{*}{ Age } & 37.4 & 31.8 \\
\hline & $(13.4)$ & $(10.4)$ \\
\hline \multicolumn{3}{|l|}{ Education } \\
\hline None & 0.04 & 0.00 \\
\hline Primary & 0.47 & 0.27 \\
\hline Some high school & 0.19 & 0.24 \\
\hline High school & 0.14 & 0.22 \\
\hline Some college & 0.09 & 0.24 \\
\hline College & 0.07 & 0.02 \\
\hline \multicolumn{3}{|l|}{ Monthly income } \\
\hline No income & 0.45 & 0.30 \\
\hline$<\mathrm{AR} \$ 1,500$ & 0.26 & 0.30 \\
\hline $\mathrm{AR} \$ 1,500-\mathrm{AR} \$ 2,500$ & 0.14 & 0.28 \\
\hline $\mathrm{AR} \$ 2,500-\mathrm{AR} \$ 5,000$ & 0.11 & 0.13 \\
\hline$>\mathrm{AR} \$ 5,000$ & 0.05 & 0.00 \\
\hline $\mathbf{N}$ & 402,000 & 43 \\
\hline
\end{tabular}




\section{Table 2: Aggregate treatment effects}

This table reports the proportions (\% of individuals contacted) of [1] individuals who presented to donate, and [2] individuals who made a blood donation that was not discarded. Treatment effects are measured as differences in proportions of donors presenting and non-discarded units of blood collected between the Information group and the control group, and between each Voucher group and the Information group. P-values are from Fisher exact tests. Significance levels are denoted with $* * * \mathrm{p}<0.01, * * \mathrm{p}<0.05, * \mathrm{p}<0.1$.

\begin{tabular}{|c|c|c|c|c|c|}
\hline \multirow[b]{2}{*}{ Outcome variable } & & \multicolumn{2}{|c|}{ [1] } & \multicolumn{2}{|c|}{ [2] } \\
\hline & & $\begin{array}{r}\text { Individu } \\
\text { to }\end{array}$ & $\begin{array}{l}\text { resenting } \\
\text { ate }\end{array}$ & $\begin{array}{l}\text { Prod } \\
\text { of blo }\end{array}$ & $\begin{array}{l}\text { units } \\
\text { llected }\end{array}$ \\
\hline & Observations & $\%$ & $\mathrm{P}$-value & $\%$ & $\mathrm{P}$-value \\
\hline Control & 2,360 & 0.042 & & 0.042 & \\
\hline Information & 2,366 & 0 & & 0 & \\
\hline T-shirt & 2,248 & 0 & & 0 & \\
\hline Newspaper & 2,411 & 0 & & 0 & \\
\hline AR\$20 Voucher & 2,253 & 0 & & 0 & \\
\hline AR $\$ 60$ Voucher & 2,336 & 0.514 & & 0.428 & \\
\hline AR $\$ 100$ Voucher & 3,264 & 1.134 & & 0.980 & \\
\hline Info-Control & & -0.042 & 0.499 & -0.042 & 0.499 \\
\hline AR\$60-Info & & $0.514^{* * *}$ & 0.000 & $0.428^{* * *}$ & 0.001 \\
\hline AR\$100-Info & & $1.134 * * *$ & 0.000 & $0.980 * * *$ & 0.000 \\
\hline AR $\$ 100-A R \$ 60$ & & $0.620 * *$ & 0.013 & $0.552 * *$ & 0.018 \\
\hline
\end{tabular}




\section{Table 3: Contacted subject direct treatment effects}

This table reports proportions (\% of individuals contacted) of [1] contacted individuals who presented to donate, and [2] contacted individuals who made a blood donation that was not discarded. Treatment effects are measured as differences in proportions of donors presenting and non-discarded units of blood collected between the Information group and the control group, and between each Voucher group and the Information group. P-values are from Fisher exact tests. Significance levels are denoted with $* * * \mathrm{p}<0.01, * * \mathrm{p}<0.05, * \mathrm{p}<0.1$.

\begin{tabular}{|c|c|c|c|c|c|}
\hline \multirow[b]{2}{*}{ Outcome variable } & & \multicolumn{2}{|c|}{ [1] } & \multicolumn{2}{|c|}{ [2] } \\
\hline & & $\begin{array}{r}\text { Individu } \\
\text { to }\end{array}$ & $\begin{array}{l}\text { esenting } \\
\text { te }\end{array}$ & $\begin{array}{l}\text { Produ } \\
\text { of bloo }\end{array}$ & $\begin{array}{l}\text { units } \\
\text { llected }\end{array}$ \\
\hline & Observations & $\%$ & P-value & $\%$ & $\mathrm{P}$-value \\
\hline Control & 2,360 & 0 & & 0 & \\
\hline Information & 2,366 & 0 & & 0 & \\
\hline T-shirt & 2,248 & 0 & & 0 & \\
\hline Newspaper & 2,411 & 0 & & 0 & \\
\hline AR\$20 Voucher & 2,253 & 0 & & 0 & \\
\hline AR\$60 Voucher & 2,336 & 0.428 & & 0.342 & \\
\hline AR $\$ 100$ Voucher & 3,264 & 0.827 & & 0.735 & \\
\hline Info-Control & & 0.000 & & 0.000 & \\
\hline AR\$60-Info & & $0.428 * * *$ & 0.001 & $0.342 * * *$ & 0.004 \\
\hline AR \$100-Info & & $0.827 * * *$ & 0.000 & $0.735^{* * *}$ & 0.000 \\
\hline AR $\$ 100-A R \$ 60$ & & $0.399 *$ & 0.093 & $0.393 *$ & 0.071 \\
\hline
\end{tabular}




\section{Table 4: Differences in walkouts, ineligible, and blood discarded}

This table presents results from Fisher's exact tests of the difference in frequencies of [1] individuals who presented at CMTH but walked out before donating, [2] individuals who presented at CMTH but were ineligible to donate, [3] individuals who presented at CMTH but were ineligible to donate or whose blood type did not match that of the intended recipient (applies only to Emergency/Replacement donors), and [4] blood units that were discarded, between the group of individuals who presented in response to the voucher treatments, and the group of individuals who presented to donate for emergency/replacement reasons in the same period. In [1] and [2], the sample consists of all individuals who presented, and in [3] it includes all individuals who performed a donation. P-values are from Fisher exact tests. Significance levels are denoted with $* * * \mathrm{p}<0.01, * * \mathrm{p}<0.05, * \mathrm{p}<0.1$.

\begin{tabular}{|c|c|c|c|c|c|c|}
\hline & & [1] & [2] & [3] & & [4] \\
\hline & Turnout & $\%$ Walkouts & $\begin{array}{c}\text { \%Ineligible } \\
\text { (excluding blood } \\
\text { type mismatch) }\end{array}$ & $\begin{array}{c}\text { \%Ineligible } \\
\text { (including blood } \\
\text { type mismatch) }\end{array}$ & Units collected & $\%$ Discarded \\
\hline Voucher & 49 & 6.12 & 4.08 & 4.08 & 44 & 4.55 \\
\hline $\begin{array}{l}\text { Emergency/Replaceme } \\
\text { nt }\end{array}$ & 3,220 & 1.74 & 3.48 & 5.58 & 2,974 & 4.04 \\
\hline $\begin{array}{l}\text { Difference (Voucher- } \\
\text { E/R) } \\
\text { (P-value) }\end{array}$ & & $\begin{array}{c}4.38^{*} \\
(0.057)\end{array}$ & $\begin{array}{c}0.60 \\
(0.688)\end{array}$ & $\begin{array}{c}-1.50 \\
(0.480)\end{array}$ & & $\begin{array}{c}0.51 \\
(0.698)\end{array}$ \\
\hline
\end{tabular}




\section{Table 5: Cost per productive unit collected}

The values in row 1 are obtained by multiplying the unit cost of printing and mailing (AR \$1.8) by the number of flyers mailed (2,500 for the AR $\$ 60$ voucher and 3,500 for the AR $\$ 100$ voucher). The values in row 3 are derived as $\mathrm{N}$. of individuals presenting*AR $\$$ value of the voucher. In row 6, we divide the total AR $\$$ cost (row 4) by the number of productive units collected (raw 5). Finally, the conversion from AR\$ to US\$ is based on an exchange rate of \$US 0.23 per AR\$.

\begin{tabular}{llcc}
\hline & & $\begin{array}{c}\text { AR } \$ 60 \\
\text { voucher }\end{array}$ & $\begin{array}{c}\text { AR } \$ 100 \\
\text { voucher }\end{array}$ \\
\cline { 3 - 4 } & & \\
[1] & AR $\$$ cost of printing+mailing & $\$ 4,500$ & $\$ 6,300$ \\
[2] & Individuals presenting & 12 & 37 \\
[3] & AR $\$$ cost of providing incentive & $\$ 720$ & $\$ 3,700$ \\
[4] Total AR $\$$ cost & $\$ 5,220$ & $\$ 10,000$ \\
[5] & Productive units collected & 10 & 32 \\
[6] & AR $\$$ cost per unit collected & $\$ 522.0$ & $\$ 312.5$ \\
& US $\$$ & $\mathrm{US} \$ 120$ & $\mathrm{US} \$ 72$ \\
\hline
\end{tabular}

